\title{
Separate administration of ammonium pyrrolidinedithiocarbamate and phorbol myristate acetate at early and late stages decreases secondary brain injury following intracerebral haemorrhage in rats via the NF-kB pathway
}

\author{
Yan Song ${ }^{1}$, Feng $\mathrm{Li}^{2}$, Zhenkuan $\mathrm{Xu}^{3}$, Qibing Huang ${ }^{1}$, Zeli Zhang ${ }^{1}$ \\ ${ }^{1}$ Department of Neurosurgical Intensive Care Unit and Emergency Neurosurgery, Qilu Hospital of Shandong University and Brain \\ Science Research Institute of Shandong University, Jinan, Shandong Province, P. R. China, ${ }^{2}$ Department of Neurosurgery, Qilu \\ Hospital of Shandong University and Brain Science Research Institute of Shandong University, Jinan, Shandong Province, P. R. China, \\ ${ }^{3}$ Department of Neurosurgery, the Second Hospital of Shandong University, Jinan, Shandong Province, P. R. China
}

\begin{abstract}
Introduction: Nuclear factor- $\mathrm{\kappa} B$ (NF- $\mathrm{\kappa} B$ ) is a critical regulator of inflammatory responses following intracerebral haemorrhage (ICH). According to our previous study, inhibiting the p65 subunit at an early stage after ICH can reduce cell death, while inhibiting c-Rel at a late stage can lead to the opposite result. The aim of this study is to clarify whether patient prognosis can be improved by inhibiting $p 65$ at the early stage and promoting c-Rel at the late stage.

Material and methods: Rats were divided into a sham group, ICH group, early NF-KB-inhibiting group using ammonium pyrrolidinedithiocarbamate (PDTC; group A, $p 65$ subunit was dominant and inhibited at the early stage), late NF- $\kappa B$-activating group using phorbol myristate acetate (PMA; group B, c-Rel was dominant and promoted at the late stage), and early NF-KB-inhibiting and late-activating group (group C, $p 65$ subunit was inhibited at the early stage and $\mathrm{c}$-Rel was promoted at the late stage). At preset time points after ICH, perihematomal tissue was obtained for detection of NF- $\mathrm{K} B$ activation, cell death, and expression of caspase-3, BCl-2, and NF-kB subunits, to evaluate of the effect of PDTC and PMA.

Results: At four days after ICH, p65 expression $(p<0.01)$ and the number of TUNEL-positive cells $(p<0.01)$ in group A were significantly lower than in the ICH group. At 10 days after ICH, $c$-Rel expression in groups $B$ and $C$ was significantly higher than in other groups ( $p<0.01$ for all). TUNEL-positive cell numbers in groups $A$ and $B$ were significantly lower than in the ICH group, though more numerous than in group $C$ ( $p<0.01$ for all).

Conclusions: Administration of both PDTC at the early stage and PMA at the late stage reduced perihematomal cell death after $I \mathrm{CH}$, and using the two reagents together had a stronger anti-apoptotic effect than separate usage.
\end{abstract}

Key words: intracerebral haemorrhage, nuclear factor- $\kappa B$, subunits, intervention, cell death.

\section{Introduction}

Intracerebral haemorrhage $(\mathrm{ICH})$ accounts for approximately $30 \%$ of all cases of stroke in China, more than twice the number in the West $[15,20,22,36]$.
These patients place a heavy burden on society and their families; hence, it is important to find ways to improve their prognosis. Previous studies revealed that a series of inflammatory responses in perihematomal 
brain tissue were triggered after $\mathrm{ICH}$ and played a key

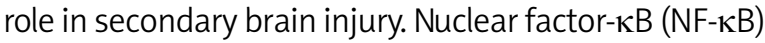
is crucial to the inflammatory responses following $\mathrm{ICH}$ $[26,30,35]$. In cells that were unstimulated, due to the

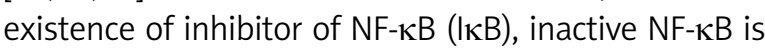
sequestered in the cytoplasm. Following $\mathrm{ICH}$, a series of factors, such as thrombin, tumour necrosis factor- $\alpha$ (TNF- $\alpha$ ), and interleukin-1 (IL-1), can cause IKB phosphorylation and $\mathrm{NF}-\mathrm{KB}$ activation, and posterior to that, free NF- $\mathrm{KB}$ migrates into the nucleus to promote gene transcription [5,28,33,34]. To date, the exact role of NF- $\mathrm{KB}$ in inflammatory responses following $\mathrm{ICH}$ is not fully understood. Previous studies showed that $\mathrm{NF}$-kB activation promotes cell death $[8,11,16]$, whereas other studies suggested the opposite $[2,18,19]$.

In our previous study, NF-KB activation after $\mathrm{ICH}$ showed biphasic distribution. NF-KB subunit p65 caused the first peak of NF- $\mathrm{KB}$ activation at 2 days (d) after $\mathrm{ICH}$, and c-Rel caused the second peak at $10 \mathrm{~d}$ after ICH [19]. Ammonium pyrrolidinedithiocarbamate (PDTC) was used to inhibit p65 and c-Rel activation. The results suggest that inhibiting p65 at an early stage after $\mathrm{ICH}$ reduces apoptosis, and inhibiting c-Rel at a late stage increases apoptosis [32]. According to the results above, we determined that c-Rel expression in the late stage after $\mathrm{ICH}$ played a neuroprotective role, whereas p65 in the early stage played the opposite role. Therefore, we concluded that both p65 inhibition at the early stage and c-Rel promotion at the late stage might reduce apoptosis more effectively. Phorbol myristate acetate (PMA) is an activator of NF-KB $[10,24,25]$. In this study, we administered PDTC at the early stage and PMA at the late stage after $\mathrm{ICH}$, and then detected changes in NF-KB activation, subunit expression, apoptosis, and apoptotic factors. Results were analysed to add to our understanding of the mechanisms described above.

\section{Material and methods}

\section{ICH model}

Male Wistar rats ( $n=64,14-16$ weeks old, 240-260 g) used in the experiment were purchased from the Laboratory Animal Centre of Shandong University and were divided into a sham group (16 rats), $\mathrm{ICH}$ group (16 rats), early NF-kB-inhibiting group (group A, 16 rats), late NF-kB-activating group (group B, 8 rats), and early NF-KB-inhibiting and late-activating group (group C, 8 rats). The environment housing the rat was kept at stable humidity and temperature $\left(21^{\circ} \mathrm{C}\right)$ on a 12-h light-dark cycle. Water and food were freely accessed. Stereotaxic intrastriatal administration of bacterial collagenase type IV (Solarbio, Beijing, China) was chosen to induce the experimental ICH, following the method previously described in the literature and used in our laboratory [9,32,35]. Briefly speaking, rats were anesthetised by intraperitoneal injection with $10 \%$ chloral hydrate $(3 \mathrm{ml} / \mathrm{kg})$ and then placed on a stereotaxic apparatus (Zhongshi Dichuang, Beijing, China). On the mid-line of the scalp, an incision was made with a surgical blade, and a burr hole was drilled. Then a micro syringe (Gaoge, Shanghai, China) was implanted into the right striatum stereotaxically (coordinates: $3.0 \mathrm{~mm}$ right to the midline, $0.2 \mathrm{~mm}$ posterior to bregma, and $6.0 \mathrm{~mm}$ below the skull). ICH was induced via administration of $1 \mu \mathrm{l}$ saline containing $0.23 \mathrm{U}$ bacterial collagenase type IV over a five-minute period. To avoid backflow, the syringe was placed in situ for another 10 minutes and then withdrawn slowly. All the holes mentioned were sealed with bone wax, and incisions were sutured. With a stereotaxic needle insertion and an injection of $1 \mu \mathrm{l}$ saline (equal volume to the $\mathrm{ICH}$ group), sham $\mathrm{ICH}$ was made. To keep the body temperature at $37 \pm 0.5^{\circ} \mathrm{C}$, the rats were put on a warm blanket.

For the rats in group A, PDTC (ab141406, Abcam, USA) was administered into the cisterna magna at 10 min, $1 \mathrm{~d}$, and $2 \mathrm{~d}$ (early stage) after the ICH model was implemented, in order to inhibit NF-KB activation. In group B, PMA (P1585, Sigma-Aldrich, USA) was administered at $6 \mathrm{~d}, 7 \mathrm{~d}$, and $8 \mathrm{~d}$ (late stage), to promote NF-KB activation. In group C, both PDTC and PMA were administered at the corresponding time points mentioned above. Administration was performed following the procedures below: rats were placed in a prone position after anaesthesia. An incision was made $2.0 \mathrm{~cm}$ below the external occipital protuberance, thus exposing the occipital bone, atlas, and atlanto-occipital membrane. Syringe needles $(1 \mathrm{ml})$ were punctured into the cisterna magna, and the cerebrospinal fluid was allowed to flow out. PDTC solution $(20 \mu \mathrm{mol} / \mathrm{l}, 0.3 \mathrm{ml})$ or PMA solution $(1.0 \mu \mathrm{mol} / \mathrm{l}, 0.3 \mathrm{ml})$ was injected into the cisterna magna within two minutes. A gelatine sponge was used to block the hole, and the incision was sutured.

Animal welfare and experimental procedures were in accordance with the Care and Use of Laboratory Animals (National Research Council, Washing- 
ton D.C., USA). The study protocol was approved by the Ethics Committee of Qilu Hospital.

\section{Tissue preparation}

Brain tissue was harvested at predefined time points, i.e. $4 \mathrm{~d}$ and $10 \mathrm{~d}$ after operation for the sham group, $\mathrm{ICH}$ group, and group $\mathrm{A}$, and $10 \mathrm{~d}$ for group $\mathrm{B}$ and group C. Rats were re-anaesthetised with 10\% chloral hydrate, and then sacrificed by trans-cardiac perfusion with cold phosphate-buffered saline (PBS), which the aim of eliminating the RNA and protein expressed by blood cells. Then, the brains were removed from the skulls quickly, followed by immediate dissection on ice to obtain half of the ipsilateral striatum, which was then flash-frozen in liquid nitrogen and stored at $-80^{\circ} \mathrm{C}$ for molecular biology experiments. The other half of the ipsilateral striatum as well as the peripheral tissue was removed with care and kept in $4 \%$ paraformaldehyde at $4^{\circ} \mathrm{C}$ for fixation for three days. After that, tissues were paraffin-embedded and processed into $5 \mu \mathrm{m}$ sections for morphological study.

\section{Electrophoretic mobility shift assay}

Nucleoprotein was extracted from the brain tissue following instructions provided by the manufacturer (Thermo Fisher Scientific Inc., USA). Protein concentrations were determined using a Micro BCA Protein Assay Kit (Thermo Fisher Scientific Inc., USA). As mentioned above, half of the nucleoprotein was stored at $-80^{\circ} \mathrm{C}$ for electrophoretic mobility shift assay (EMSA), and the other was for western blotting. A LightShift ${ }^{\text {TM }}$ Chemiluminescent EMSA Kit (Thermo Scientific, 20148, USA) was used for EMSA. A 5'-biotin-labeled NF-kB oligo (5'-AGTTGAGGGGACTTTCCCAGGC-3') was used as the probe. EMSA was performed as instructed by the manufacturer.

A fully automated chemiluminescence imaging analysis system (Tanon 5200, China) with associated software was used to visualise and analyse all immunoblots.

\section{Western blotting}

The extracted nucleoprotein samples described previously were boiled for 10 minutes, loaded onto a $14 \%$ SDS-PAGE gel, and subjected to electrophoresis at $100 \mathrm{~V}$ for two hours. Protein was electrophoretically transferred onto a $0.22 \mathrm{~m}$ nitrocellulose membrane and immunoblotted with primary antibodies
NF-KB p65 (ab19870 rabbit polyclonal, Abcam, USA, concentration: $2.5 \mu \mathrm{g} / \mathrm{ml}$ ), NF-kB c-Rel (12707 rabbit monoclonal, CST, USA, dilution: $1: 1000$ ), and Lamin A, respectively, and then with secondary antibody (Peroxidase-AffiniPure Goat Anti-Rabbit IgG [H + L], Jackson ImmunoResearch, USA, dilution: $1: 10000$ ).

Total protein was extracted by lysing the prepared tissue at $4^{\circ} \mathrm{C}$ for 30 minutes in lysis buffer $(20 \mathrm{mM}$ tris [hydroxymethyl] aminomethane- $\mathrm{HCl}, \mathrm{pH} 7.5$, $140 \mathrm{mM} \mathrm{NaCl}, 1 \mathrm{mM}$ ethylenediaminetetraacetic acid, $50 \mathrm{U} / \mathrm{ml}$ aprotinin, $1 \mathrm{mM}$ phenylmethylsulphonyl fluoride, and $1 \mathrm{mM}$ sodium orthovanadate) containing 1\% Nonidet P-40 detergent. Protein concentrations were determined using Micro BCA Protein Assay Kit (Thermo Fisher Scientific Inc., USA). The total protein samples were boiled for 10 minutes, loaded onto a 14\% SDS-PAGE gel, and electrophoresis was conducted at $100 \mathrm{~V}$ for two hours. Proteins were electrophoretically transferred onto $0.22 \mathrm{~m}$ nitrocellulose and immunoblotted with primary antibodies for caspase-3 (9665 rabbit monoclonal, CST, USA, dilution: $1: 1000$ ), Bcl-2 (ab59348 rabbit polyclonal, Abcam, USA, dilution: 1 : 1000), and $\beta$-actin, respectively, and then with secondary antibody (Peroxidase-AffiniPure Goat Anti-Rabbit IgG $(\mathrm{H}+\mathrm{L})$, Jackson ImmunoResearch, USA, dilution: $1: 10000$ ).

A fully automated chemiluminescence imaging analysis system (Tanon 5200, China) with associated software was used to visualise and analyse all immunoblots.

\section{Terminal deoxynucleotidyl transferase-mediated dUTP-biotin nick end labelling (TUNEL) assay}

Tissue sections were deparaffinised and hydrated, then the TUNEL assay was performed following instructions provided by the manufacturer (In Situ Cell Death Detection Kit, POD, Roche, Germany). Samples were incubated in the TUNEL reaction mixture and rinsed with PBS. After incubation in DAB substrate solution, samples were rinsed and mounted under glass cover slips, and slides were analysed by light microscope by three professors of pathology in a blinded fashion. The basal ganglia, which is rich in neurons, is the region of interest for TUNEL analysis. A total of five no-repeat fields (400x magnification) were randomly selected, the TUNEL-positive cells were identified, and the numbers of positive cells in all five fields were summed to obtain the 
result. The results recorded by the three pathologists were consistent.

\section{Statistical analysis}

For statistical analysis and charting, SPSS 22.0 statistical analysis software and Excel 2016 were used. The normally distributed continuous variables were expressed as mean \pm standard deviation and were analysed with Student's $t$-test. The least significant difference was used for the multiple comparisons. Statistical significance was set at $p<0.05$.

\section{Results}

\section{ICH model}

There was no evidence indicating $\mathrm{ICH}$ in the sham group, nor death due to ICH in any group. The haematoma was located in the basal ganglia, and the homogeneity of haematoma volume was good.

\section{Electrophoretic mobility shift assay}

$\mathrm{NF}-\mathrm{kB}$ activation was detected by EMSA. The NF- $\mathrm{KB}$ activation level in the ICH group was significantly higher than in the sham group $4 \mathrm{~d}$ after ICH $(p<0.01)$. In group $\mathrm{A}$, administering PDTC in the early stage after $\mathrm{ICH}$ significantly reduced NF- $\mathrm{KB}$ activation $(p<0.01)$, which was still higher than in the sham group $(p<0.01)$. At $10 \mathrm{~d}$ after $\mathrm{ICH}$, there was a significant difference in NF-KB activation between the sham group and each of the other groups $(p<0.01)$. NF-kB activation levels in group B $(p<0.01)$ and group $C(p<0.01)$, in which PMA was administered in the late stage after $\mathrm{ICH}$, were higher than in the $\mathrm{ICH}$ group, while there was no significant difference between group $\mathrm{A}$ and the ICH group $(p>0.05)$. The results above suggest that PDTC can inhibit NF-KB activation, and that PMA has the opposite function (Fig. 1).

\section{P65 and c-Rel expression}

At $4 \mathrm{~d}$ after $\mathrm{ICH}$, the expression level of p65 significantly increased in the $\mathrm{ICH}$ group compared with the sham group $(p<0.01)$, while that of $c$-Rel showed no significant difference $(p>0.05)$. PDTC administration at the early stage after $\mathrm{ICH}$ in group A significantly reduced the expression of p65 $(p<0.01)$ but not of c-Rel $(p>0.05)$. At $10 \mathrm{~d}$ after ICH, both p65 $(p<0.01)$ and $c-$ Rel $(p<0.01)$ expression levels were significantly lower in the sham group than in the other groups. There were no significant differences in p65 expression among the $\mathrm{ICH}$ group and groups $\mathrm{A}$, $\mathrm{B}$, and $\mathrm{C}(p>0.05)$. Compared with the $\mathrm{ICH}$ group and group A, PMA administration at the late stage after ICH significantly increased c-Rel expression in groups $B$ and $C(p<0.01$ for all). The results above suggest that PDTC administration at the early stage after $\mathrm{ICH}$ can reduce NF- $\mathrm{KB}$ activation by inhibiting p65 expression, while PMA administration at the late stage after ICH can increase NF- $\mathrm{KB}$ activation by promoting c-Rel expression (Fig. 2).

\section{Caspase- 3 and $\mathrm{Bcl}-2$ expression}

Both caspase-3 and $\mathrm{BCl}-2$ are apoptosis-related factors. At $4 \mathrm{~d}$ after $\mathrm{ICH}$, caspase-3 expression increased significantly in the $\mathrm{ICH}$ group compared with the sham group $(p<0.01)$ and decreased significantly in group A $(p<0.01)$. The opposite trend was observed for Bcl-2 expression, which decreased

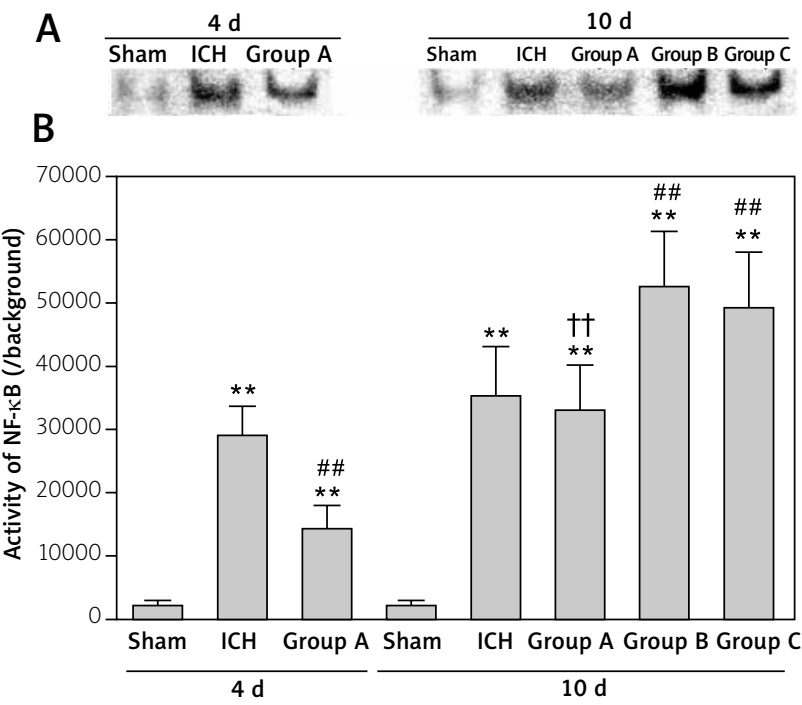

Fig. 1. Activation profiling and column chart of NF- $\kappa$ B. A) The representative EMSA result showed the NF- $\mathrm{B}$ B activity in each group. $\mathrm{B}$ ) The level of $N F-\kappa B$ activation in each experimental group was significantly higher than that in the sham group. At $4 \mathrm{~d}$ after $\mathrm{ICH}$, administrating PDTC in group A significantly reduced NF- $\kappa B$ activation compared with the $\mathrm{ICH}$ group. Then at $10 \mathrm{~d}$ after $\mathrm{ICH}$, NF- $\kappa \mathrm{B}$ activation levels in group $\mathrm{B}$ and group $\mathrm{C}$ were significantly higher than that in $\mathrm{ICH}$ group, while there was no significant difference between group $\mathrm{A}$ and the $\mathrm{ICH}$ group. Bars represent mean $\pm \mathrm{SD}$ ( $n=8$, each group), ${ }^{\star *} p<0.01 \mathrm{vs}$. sham group, ${ }^{\# \#} p<0.01$ vs. ICH group, ${ }^{+\dagger} p<0.01$ vs. group C. 
A

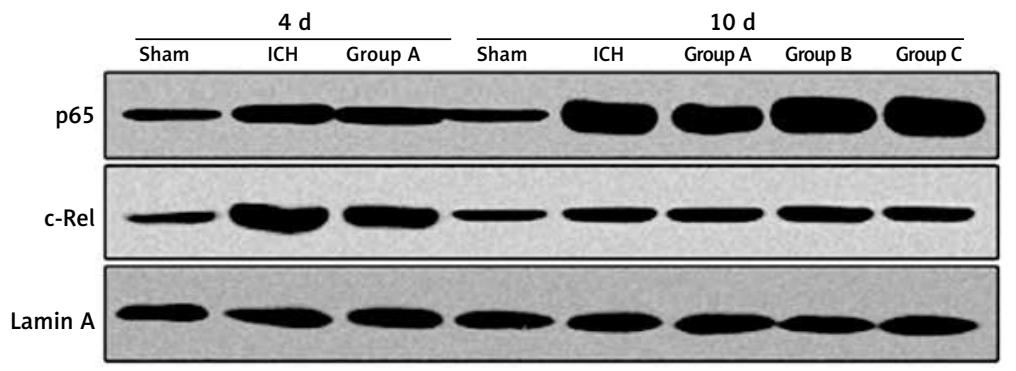

B

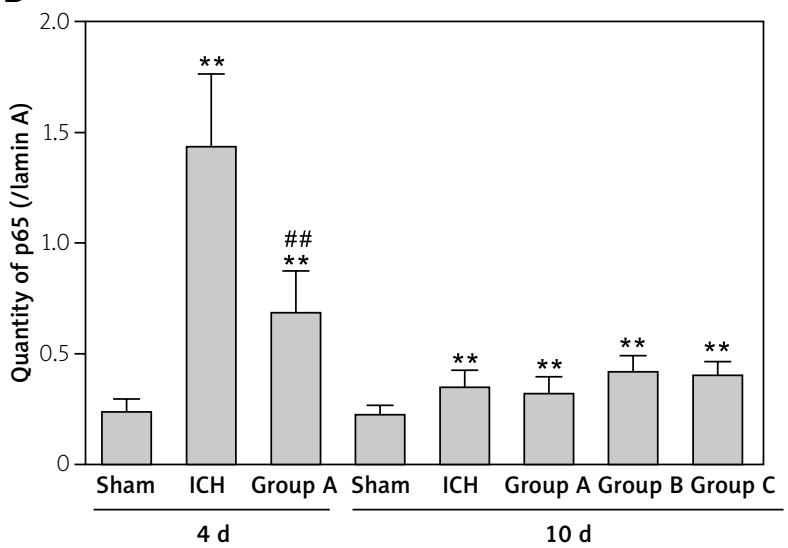

C

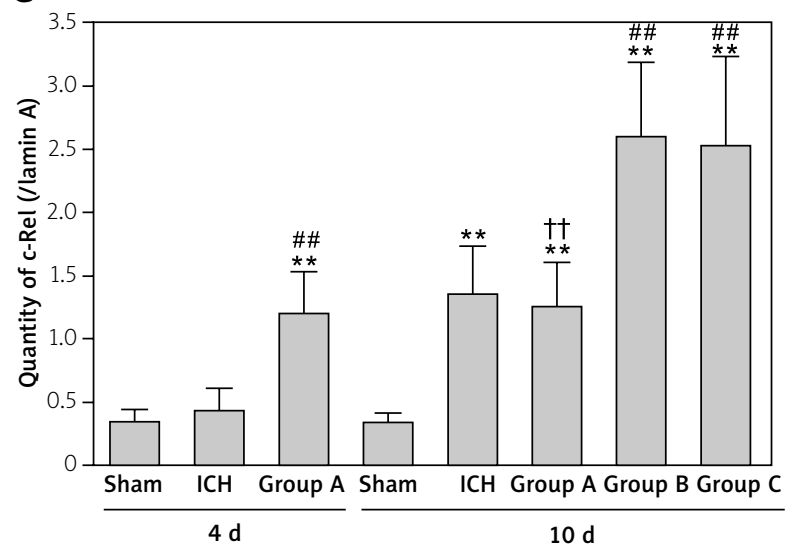

Fig. 2. Expression profiling and column chart of p65 and c-Rel in nucleoprotein. A) The representative western blotting result showed the expression of p65 and c-Rel in each group. B, C) Column chart shows that p65 mainly expressed at the early stage after $\mathrm{ICH}$, and c-Rel at the late stage. At $4 \mathrm{~d}$ after $\mathrm{ICH}$, the expression of p65 was significantly lower than that in the ICH group. At $10 \mathrm{~d}$ after ICH, compared with the ICH group and group A, PMA administration at the late stage after ICH significantly increased the c-Rel expression in group $B$ and C. Bars represent mean $\pm S D$ ( $n=8$, each group), ${ }^{* *} p<0.01$ vs. sham group, ${ }^{\# \#} p<0.01 \mathrm{vs}$. ICH group, ${ }^{\dagger \dagger} p<0.01$ vs. group $C$.

significantly in the $\mathrm{ICH}$ group compared with the sham group $(p<0.01)$ and increased significantly in group A compared with the ICH group $(p<0.01)$. At $10 \mathrm{~d}$ after $\mathrm{ICH}$, caspase-3 expression in each of the other groups was significantly higher than in the sham group ( $p<0.01$ for all), while that in group $C$ was lower than in $\mathrm{ICH}$ group, group $\mathrm{A}$, or group $\mathrm{B}$ $(p<0.01$ for all). Bcl-2 expression in the $\mathrm{ICH}$ group, group $A$, and group $B$ was significantly lower than in the sham group ( $p<0.01$ for all), while there was no significant difference between group $C$ and the sham group ( $p>0.05)$. PDTC administration at the early stage in group $\mathrm{A}$ did not increase $\mathrm{Bcl}-2$ expression at $10 \mathrm{~d}$ after ICH compared with the ICH group $(p>0.05)$, while PMA administration at the late stage in group $B$ and $C$ did $(p<0.01)$. It is noteworthy that $\mathrm{Bcl}-2$ expression in group $C$ nearly reached the level in the sham group $(p>0.05)$ (Fig. 3).

\section{TUNEL assay}

Cell death was detected by TUNEL assay. At $4 \mathrm{~d}$ after ICH, TUNEL-positive cells in the ICH group significantly increased compared with the sham group $(p<0.01)$, while those in group A decreased significantly $(p<0.01)$. At $10 \mathrm{~d}$ after ICH, TUNEL-positive cells in group $A$ and $B$ were significantly fewer than in the ICH group $(p<0.01)$ but still significantly more numerous than in group $C(p<0.01)$. The results above demonstrate that administering PDTC at the early stage combined with PMA at the late stage can have stronger anti-apoptotic effects than either of them administered alone (Fig. 4).

\section{Discussion}

The main findings of the present study were as follows: 1) NF-KB activation can be inhibited by 
A

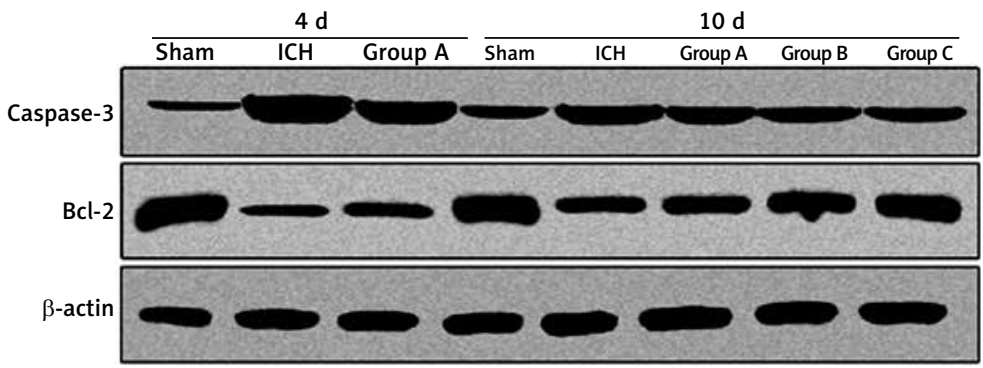

B

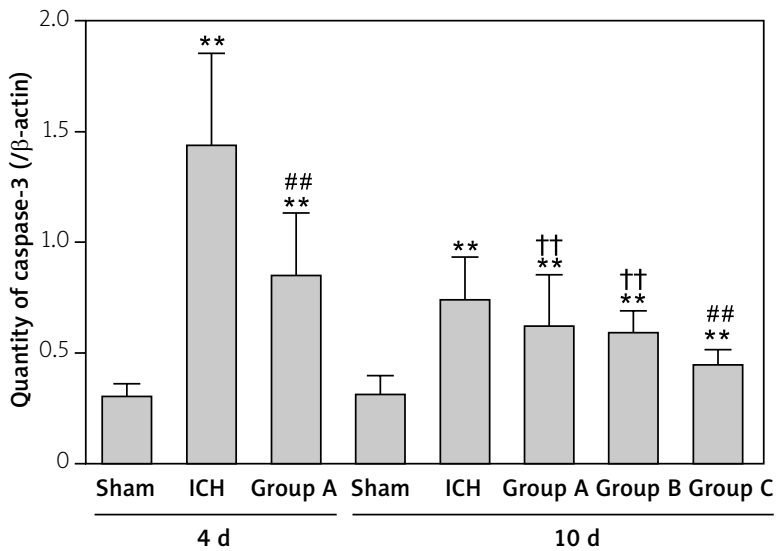

C

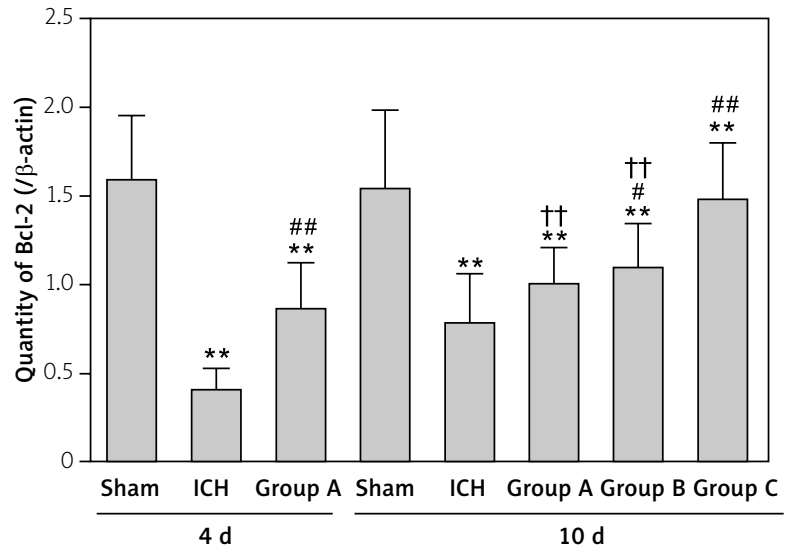

Fig. 3. Expression profiling and column chart of $\mathrm{Bcl}-2$ and caspase-3. A) The representative western blotting showed the Bcl-2 and caspase-3 in each group. B, C) Column chart showed that at $4 \mathrm{~d}$ after ICH, caspase-3 expression increased significantly in the $\mathrm{ICH}$ group compared with the sham group, and decreased significantly in group A, while the opposite trend was displayed for $\mathrm{Bcl}-2$ expression. At $10 \mathrm{~d}$ after ICH, caspase-3 expression in group $\mathrm{C}$ was lower than that in the $\mathrm{ICH}$ group, group $\mathrm{A}$, and group $\mathrm{B}$, respectively. The expressions of $\mathrm{BCl}-2$ in the $\mathrm{ICH}$ group, group $\mathrm{A}$, and group $\mathrm{B}$ were significantly lower than that in the sham group, and there was no significant difference between group $C$ and the sham group. Bars represent mean \pm SD ( $n=8$, each group), ${ }^{* *} p<0.01$ vs. sham group, ${ }^{\#} p<0.05$ vs. ICH group, ${ }^{\# \#} p<0.01$ vs. ICH group, ${ }^{\dagger \dagger} p<0.01$ vs. group $\mathrm{C}$.

administrating PDTC at an early stage after $\mathrm{ICH}$, and it is promoted by PMA at the late stage; 2) NF- $\mathrm{KB}$ subunit p65 is mainly expressed at the early stage after $\mathrm{ICH}$, and $\mathrm{c}$-Rel at the late stage. PDTC reduced $N F-\kappa B$ activation in the early stage after $\mathrm{ICH}$ by inhibiting p65 expression, and PMA increased NF- $\mathrm{KB}$ activation in the late stage via promotion of c-Rel expression; 3) Administering both PDTC at the early stage and PMA at the late stage produced a stronger anti-apoptotic effect than applying either of the two treatments respectively.

$N F-\kappa B$, which has been recognised as a critical regulator of inflammatory responses since its discov-

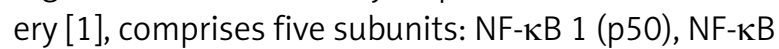
2 (p52), RelA (p65), RelB, and c-Rel. Dimerisation of $N F-\kappa B /$ Rel protein family members is required.
In unstimulated cells, inactive dimerised $N F-\kappa B$ is sequestered in the cytoplasm by $I_{\kappa} B$, which can be rapidly phosphorylated and degraded by a wide array of factors [16]. Then, the free NF- $\kappa B$ rapidly migrates into the nucleus, binds to DNA, and promotes the transcription of genes for the release of inflammatory substances. Different NF- $\mathrm{KB} /$ Rel dimers have different functions. Cells can regulate the expression of genes based on selection of slightly different $\kappa B$ sequences and dimers with different affinities under different stimuli or physiological states $[7,12,13]$.

PMA promotes NF- $\kappa B$ activation $[10,24,25]$. As a cytoplasmic enzyme, protein kinase C (PKC) participates in intracellular biochemical responses and regulates nuclear transcription factors such as NF- $\kappa B$. PMA, one of the most commonly used phorbol esters, 
A

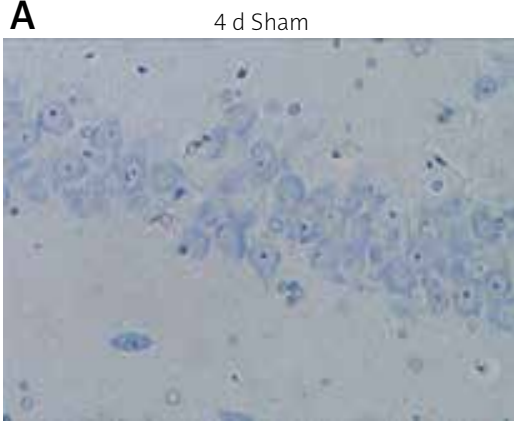

D
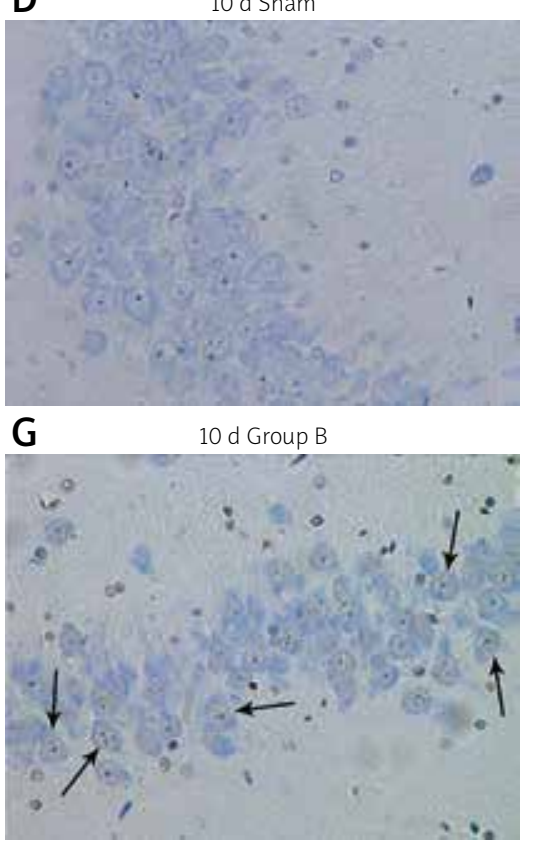

$\mathrm{H}$

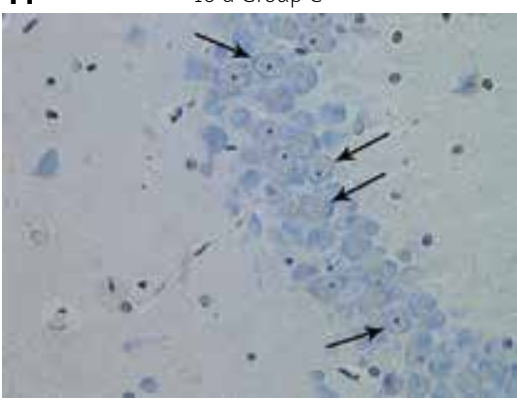

$10 \mathrm{~d}$ Group C
B

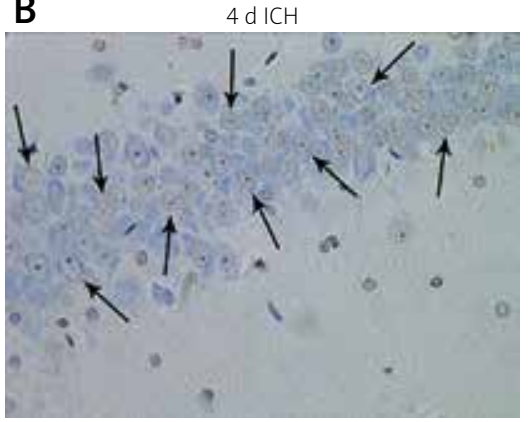

$\mathrm{E}$

$10 \mathrm{~d} \mathrm{ICH}$

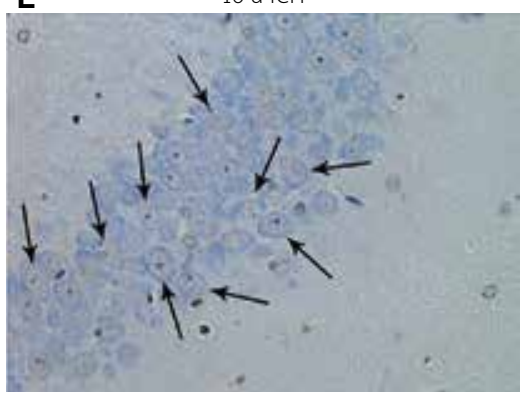

\section{$\mathrm{F}$}

C

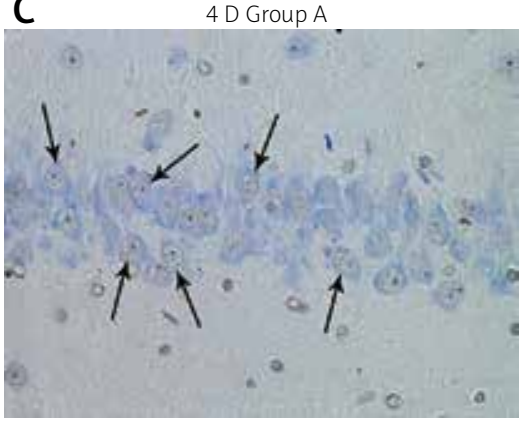

F $10 d$ Group A

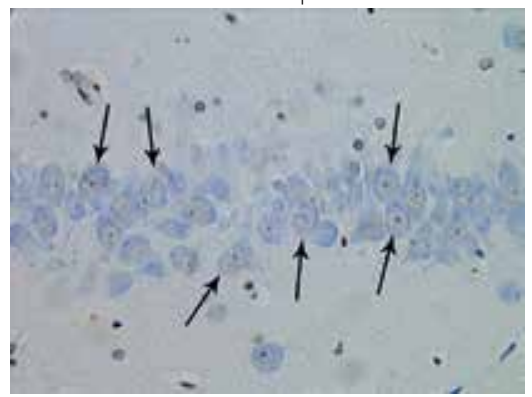

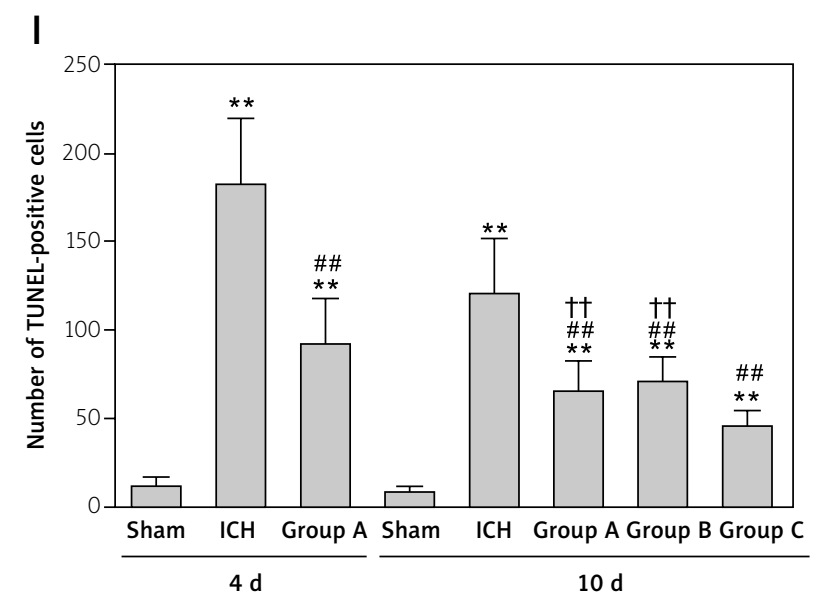

Fig. 4. Microscopic images and column chart of cell death detected with TUNEL assay. A-H) Microscopic images (400x) of the sham and each experimental group showed the TUNEL-positive cells. I) Column chart showed that at $4 \mathrm{~d}$ after ICH, the number of TUNEL-positive cells in group A was significantly lower than that in the ICH group. At $10 \mathrm{~d}$ after ICH, the number of TUNEL-positive cells in group A and B was significantly lower than that in the ICH group, but still significantly more than that in group C. $\rightarrow$ indicate TUNEL-positive cells. Bars represent mean \pm SD ( $n=8$, each group), ${ }^{\star \star} p<0.01$ vs. sham group, ${ }^{\# \#} p<0.01$ vs. ICH group, ${ }^{\dagger+} p<0.01$ vs. group C.

can activate the PKC system to produce a series of cellular responses. Regulating the level of protein expression by NF-KB is one of these responses. PMA therefore has the effect of promoting NF-KB activation. PDTC has many functions in biological systems, one of which is inhibiting NF-KB activation, 
according previous studies by our group and others $[6,14,23,31]$. One mechanism is that PDTC can inhibit I $\mathrm{KB}$ phosphorylation and NF-KB activation, reducing the free NF- $\mathrm{KB}$ that migrates into the nucleus to promote gene transcription. Another mechanism is that PDTC acts as an antioxidant, scavenging oxygen free radicals, which can induce NF- $\mathrm{KB}$ activation.

According to our previous study, NF- $\mathrm{KB}$ activation after ICH shows a biphasic distribution mode due to its subunits, including p65 and c-Rel. P65 caused the first peak of NF-kB activation at $2 \mathrm{~d}$ after ICH, synchronous with the expression peak of inflammatory factors, apoptotic factor, and apoptosis, while c-Rel caused the second peak at $10 \mathrm{~d}$ after $\mathrm{ICH}$, synchronous with the decline of inflammatory factors and apoptosis [35]. In our further study, PDTC was used to inhibit p65 and c-Rel activation. The results suggest that inhibiting p65 in the early stage after ICH can reduce apoptosis, and inhibiting c-Rel at the late stage can have the opposite effect [32]. According to the results above, we conclude that c-Rel expression at the late stage after $\mathrm{ICH}$ plays a neuroprotective role, and p65 at the early stage plays the opposite role. In this study, we administered PDTC to inhibit p65 at the early stage and PMA to promote c-Rel at the late stage, and then analysed the results to clarify whether these measures could reduce cell death more effectively.

Previous studies of human and animal models of $\mathrm{ICH}$ indicated that there was a close relationship between NF- $\mathrm{KB}$ activation, cell death, and prognosis $[2,16,33,34]$. Bcl-2 has been proven to promote neuronal regeneration and survival and have anti-apoptotic effects $[3,18,29]$, while caspase-3 can cleave poly (ADP-ribose) polymerase, a protein related to DNA repair and genetic integrity, into two fragments and have an apoptosis-promoting effect $[4,17,21,27]$. In this study, cell death and apoptosis-related factors $\mathrm{Bcl}-2$ and caspase- 3 were detected by TUNEL and western blotting, respectively, to verify the effect of our intervention.

The timing of PDTC or PMA administration significantly affected their effectiveness in reducing cell death. The timing of intervention in this study was determined according to p65 and c-Rel expression trends after $\mathrm{ICH}$. In our previous study, p65 expression increased at $6 \mathrm{~h}$ after $\mathrm{ICH}$, peaked at $2 \mathrm{~d}$, then decreased and returned to normal at $10 \mathrm{~d}$, while c-Rel increased at $4 \mathrm{~d}$ after ICH, peaked at $10 \mathrm{~d}$, and then decreased. Therefore, in this study, PDTC was administered at 10 min, $1 \mathrm{~d}$, and $2 \mathrm{~d}$ (early stage) after ICH to inhibit p65 expression, while PMA was administered at $6 \mathrm{~d}, 7 \mathrm{~d}$, and $8 \mathrm{~d}$ (late stage) to promote c-Rel expression. The trend of p65 and c-Rel expression detected by western blotting confirmed the functions of PDTC and PMA. The results of the TUNEL assay suggested that both PDTC administration at the early stage and PMA at the late stage reduced perihematomal cell death after $\mathrm{ICH}$, and using the two measures together (group C) had a stronger anti-apoptotic effect than separate usage (group A and B). The changing trends of anti-apoptotic factor Bcl-2 and apoptosis-promoting factor caspase- 3 were also found to be closely matched to the trend of cell death according to their corresponding apoptosis-related functions.

In summary, the novelty of this study is that different interventions were applied at different stages after ICH. The p65 subunit was inhibited at the early stage after ICH using NF-kB inhibitor PDTC, while $c$-Rel subunit was promoted at the late stage using NF- $\mathrm{KB}$ promotor PMA. According to the results, we can conclude that PDTC and PMA administration at early and late stages, respectively, can attenuate secondary brain injury and reduce cell death after ICH in rats via the NF- $\mathrm{kB}$ pathway. Therefore, we can speculate that different interventions involving NF- $\kappa B$ in different periods after human $\mathrm{ICH}$ may reduce secondary brain damage and improve prognosis. The results of the present study can provide important evidence for the feasibility of further studies.

\section{Conclusions}

In the present study, we found that PDTC reduced $N F-K B$ activation at the early stage after $\mathrm{ICH}$ by inhibiting p65 expression, and PMA increased NF- $\mathrm{KB}$ activation at the late stage via promotion of c-Rel expression. Administration of both PDTC at the early stage and PMA at the late stage reduced perihematomal cell death after $\mathrm{ICH}$, and using the two measures together produced a stronger anti-apoptotic effect than separate usage. Therefore, we can speculate that different interventions targeting NF- $\mathrm{KB}$ at different periods after human $\mathrm{ICH}$ may reduce secondary brain damage and improve the prognosis.

\section{Acknowledgements}

This work was supported by the National Natural Science Foundation of China (81501054) and the Key 


\section{Research and Development Program of Shandong Province (2017GSF218028).}

\section{Disclosure}

\section{The authors report no conflict of interest.}

\section{References}

1. Barnes PJ, Karin M. Nuclear factor-kappa B: a pivotal transcription factor in chronic inflammatory diseases. N Engl J Med 1997; 336: 1066-1071.

2. Bhakar AL, Tannis LL, Zeindler C, Russo MP, Jobin C, Park DS, MacPherson S, Barker PA. Constitutive nuclear factor-kappa B activity is required for central neuron survival. J Neurosci 2002; 22: 8466-8475.

3. Bobinger T, Burkardt P, Huttner HB, Manaenko A. Programmed cell death after intracerebral hemorrhage. Curr Neuropharmacol 2018; 16: 1267-1281.

4. Choi KS, Kim HJ, Do SH, Hwang SJ, Yi HJ. Neuroprotective effects of hydrogen inhalation in an experimental rat intracerebral hemorrhage model. Brain Res Bull 2018; 142: 122-128.

5. Denes A, Pinteaux E, Rothwell NJ, Allan SM. Interleukin-1 and stroke: biomarker, harbinger of damage, and therapeutic target. Cerebrovasc Dis 2011; 32: 517-527.

6. Gao P, Gao YJ, Liang HL. Effect of NF-kB inhibitor PDTC on VEGF and endostatin expression of mice with Lewis lung cancer. Asian Pac J Trop Med 2015; 8: 220-224.

7. Hayden MS, Ghosh S. Signaling to NF-kappaB. Genes Dev 2004; 18: 2195-2224

8. Hu YY, Huang M, Dong XQ, Xu QP, Yu WH, Zhang ZY. Ginkgolide B reduces neuronal cell apoptosis in the hemorrhagic rat brain: possible involvement of Toll-like receptor 4/nuclear factor-kappa B pathway. J Ethnopharmacol 2011; 137: 1462-1468.

9. Jung KH, Chu K, Jeong SW, Han SY, Lee ST, Kim JY, Kim M, Roh JK. HMG-CoA reductase inhibitor, atorvastatin, promotes sensorimotor recovery, suppressing acute inflammatory reaction after experimental intracerebral hemorrhage. Stroke 2004; 35: 1744-1749.

10. Lee W, Nam JH, Cho HJ, Lee JY, Cho WK, Kim Y, We YM, Ma JY, Hoe HS. Epimedium koreanum Nakai inhibits PMAinduced cancer cell migration and invasion by modulating NF-KB/MMP-9 signaling in monomorphic malignant human glioma cells. Oncol Rep 2017; 38: 3619-3631.

11. Liu ZC, Meng LQ, Song JH, Gao J. Dynamic protein expression of $\mathrm{NF}-\mathrm{kB}$ following rat intracerebral hemorrhage and its association with apoptosis. Exp Ther Med 2018; 16: 3903-3908.

12. Mattson MP, Meffert MK. Roles for NF-kappaB in nerve cell survival, plasticity, and disease. Cell Death Differ 2006; 13: 852-860.

13. Miraghazadeh B, Cook MC. Nuclear factor-kappaB in autoimmunity: man and mouse. Front Immunol 2018; 9: 613.

14. Qin JD, Cao ZH, Li XF, Kang XL, Xue Y, Li YL, Zhang D, Liu XY, Xue YZ. Effect of ammonium pyrrolidine dithiocarbamate (PDTC) on NF-KB activation and CYP2E1 content of rats with immunological liver injury. Pharm Biol 2014; 52: 1460-1466.
15. Qureshi AL, Tuhrim S, Broderick JP, Batjer HH, Hondo H, Hanley DF. Spontaneous intracerebral hemorrhage. N Engl J Med 2001; 344: 1450-1460.

16. Ridder DA, Schwaninger M. NF-אB signaling in cerebral ischemia. Neuroscience 2009; 158: 995-1006.

17. Shen J, Zhou T, Li H, Li W, Wang S, Song Y, Ke K, Cao M. Cab45s inhibits neuronal apoptosis following intracerebral hemorrhage in adult rats. Brain Res Bull 2018; 143: 36-44.

18. Shen X, Ma L, Dong W, Wu Q, Gao Y, Luo C, Zhang M, Chen X, Tao $L$. Autophagy regulates intracerebral hemorrhage induced neural damage via apoptosis and NF-KB pathway. Neurochem Int 2016; 96: 100-112.

19. Song YS, Lee YS, Narasimhan P, Chan PH. Reduced oxidative stress promotes NF- $\mathrm{KB}$-mediated neuroprote ctive gene expression after transient focal cerebral ischemia: lymphocytotrophic cytokines and antiapoptotic factors. J Cereb Blood Flow Metab 2007; 27: 764-775.

20. Steiner T, Al-Shahi Salman R, Beer R, Christensen H, CordonnierC, Csiba L, Forsting M, Harnof S, Klijn CJ, Krieger D, Mendelow AD, Molina C, Montaner J, Overgaard K, Petersson J, Roine RO, Schmutzhard E, Schwerdtfeger K, Stapf C, Tatlisumak T, Thomas BM, Toni D, Unterberg A, Wagner M, European Stroke Organisation. European Stroke Organisation (ESO) guidelines for the management of spontaneous intracerebral hemorrhage. Int J Stroke 2014; 9: 840-855.

21. Sun DB, Xu MJ, Chen QM, Hu HT. Significant elevation of serum caspase-3 levels in patients with intracerebral hemorrhage. Clin Chim Acta 2017; 471: 62-67.

22. Tsai CF, Thomas B, Sudlow CL. Epidemiology of stroke and its subtypes in Chinese vs white populations: a systematic review. Neurology 2013; 81: 264-272.

23. Wan D, Wu Q, Qu W, Liu G, Wang X. Pyrrolidine dithiocarbamate (PDTC) inhibits DON-induced mitochondrial dysfunction and apoptosis via the NF- B/iNOS pathway. Oxid Med Cell Longev 2018; 2018: 1324173.

24. Wang JJ, Huan SK, Hsieh KH, Chou HC, Hsiao G, Jayakumar T, Sheu JR. Inhibitory effect of midazolam on MMP-9, MMP-1 and MMP-13 expression in PMA-stimulated human chondrocytes via recovery of NF-KB signaling. Arch Med Sc 2013; 9: 332-339.

25. Wen HC, Huo YN, Chou CM, Lee WS. PMA inhibits endothelial cell migration through activating the PKC- $\delta /$ Syk/NF-kB-mediated up-regulation of Thy-1. Sci Rep 2018; 8: 16247.

26. Wen J, Yang CY, Lu J, Wang XY. Ptprj-as1 mediates inflammatory injury after intracerebral hemorrhage by activating NF-אB pathway. Eur Rev Med Pharmacol Sci 2018; 22: 2817-2823.

27. Xu H, Cao J, Xu J, Li H, Shen H, Li X, Wang Z, Wu J, Chen G. GATA4 regulates neuronal apoptosis after intracerebral hemorrhage via the NF- $\mathrm{kB} / \mathrm{Bax} /$ caspase-3 pathway both in vivo and in vitro. Exp Neurol 2019; 315: 21-31.

28. Yin M, Chen Z, Ouyang Y, Zhang H, Wan Z, Wang H, Wu W, Yin X. Thrombin-induced, TNFR-dependent miR-181c downregulation promotes MLL1 and NF-KB target gene expression in human microglia. J Neuroinflammation 2017; 14: 132.

29. Yuan D, Shen J, Yan Y, Wu X, Li A, Guo A, Wu Y, Duan C, Shen J, Tang C, Zhang D, Ji Y. Upregulated expression of SSTR1 is involved in neuronal apoptosis and is coupled to the reduction 
of Bcl-2 following intracerebral hemorrhage in adult rats. Cell Mol Neurobiol 2014; 34: 951-961.

30. Zeng J, Chen Y, Ding R, Feng L, Fu Z, Yang S, Deng X, Xie Z, Zheng S. Isoliquiritigenin alleviates early brain injury after experimental intracerebral hemorrhage via suppressing ROS- and/or NF-kB-mediated NLRP3 inflammasome activation by promoting Nrf2 antioxidant pathway. J Neuroinflammation 2017; 14: 119.

31. Zhang HM, Sang XG, Wang YZ, Cui C, Zhang L, Ji WS. Role of $\Delta 133 p 53$ isoform in NF-kB inhibitor PDTC-mediated growth inhibition of MKN45 gastric cancer cells. World J Gastroenterol 2017; 23: 2716-2722.

32. Zhang Z, Song Y, Li F, X Z Z, Huang Q. Inhibiting nuclear factor-кB at different stages after intracerebral hemorrhage can influence the hemorrhage-induced brain injury in experimental models in vivo. Brain Res Bull 2019; 155: 159-165.

33. Zhang ZL, Liu YG, Huang QB, Su Y, Zhang Y, Wang G, Li F. NF-KB activation and cell death after intracerebral hemorrhage in patients. Neurol Sci 2014; 35: 1097-1102.

34. Zhang ZL, Liu YG, Huang QB, Wang HW, Song Y, Xu ZK, Li F. Nuclear factor- $\mathrm{KB}$ activation in perihematomal brain tissue correlates with outcome in patients with intracerebral hemorrhage. J Neuroinflammation 2015; 12: 53.

35. Zhang ZL, Song Y, Li F, Huang QB. Bimodal distribution of nuclear factor- $\mathrm{KB}$ activation and expression of subunits in experimental models of intracerebral hemorrhage in vivo. J Stroke Cerebrovasc Dis 2019; 28: 821-829.

36. Zhao XR, Gonzales N, Aronowski J. Pleiotropic role of PPAR $\gamma$ in intracerebral hemorrhage: an intricate system involving Nrf2, RXR, and NF-kB. CNS Neurosci Ther 2015; 21: 357-366. 